\title{
Bazı Oksim Bileşiklerinin Bağlanma Özelliklerinin Moleküler Kenetlenme Yöntemiyle İncelenmesi
}

\author{
Ömer AYSAN1 1 , Bülent DEDE*2@ \\ 1,2Süleyman Demirel Üniversitesi, Fen Edebiyat Fakültesi, Kimya Bölümü, 32260, Isparta, Türkiye
}

(Alınış / Received: 25.12.2019, Kabul / Accepted: 13.05.2020, Online Yayınlanma / Published Online: 20.08.2020)

Anahtar Kelimeler
Oksim,
DFT,
Protein,
Ligand,
Moleküler kenetlenme

Anahtar Kelimeler

DFT,

Moleküler kenetlenme

\begin{abstract}
Özet: Bu çalışmada, biyolojik aktivite gösterme potansiyeli yüksek olan bazı oksim bileşiklerinin, seçilmiş bazı proteinlerin aktif bölgesine bağlanma özellikleri moleküler kenetlenme (Doking) yöntemiyle incelenmiştir. Bu amaçla çalışllan tüm oksim ligand molekülleri, Yoğunluk Fonksiyonel Teorisi (DFT) yöntemiyle B3LYP fonksiyoneli ve 6-311G(d,p) temel seti kullanılarak Gaussian09 programında optimize edilmiştir. Optimize edilen tüm moleküllerin HOMO, LUMO ve HOMOLUMO enerji farkları hesaplanmıştır. Çalışılan ligandlar için belirlenen kuantum kimyasal parametreleri ve inhibisyon aktiviteleri arasındaki ilişki de araştırılmıştır. Ligand moleküllerinin seçilen proteinlerle moleküler kenetlenme yöntemiyle bağlantı çalışmaları, ligandların optimize edilmiş geometrileri kullanılarak gerçekleştirilmiştir. Protein veri bankasından, seçilen proteinlerin kristal yapıları *.pdb formatında temin edilmiş ve bu kristal yapıların optimize ligandlarla etkileşimi SwissDock web sunucusu kullanılarak incelenmiștir. Moleküler kenetlenme çalışmaları sonucu, ligand-protein bağlanma enerjileri, ligand-protein arasında oluşabilecek hidrojen bağ bölgeleri ve sayısı tespit edilerek değerlendirilmiştir.
\end{abstract}

\section{Investigation of Binding Properties of Some Oxime Compounds by Molecular Docking Method}

Keywords

Oxime,

DFT,

Protein,

Ligand,

Molecular docking

\begin{abstract}
In this study, the binding properties of some oxime compounds which have high biological activity potential to the active site of selected proteins were investigated by molecular docking method. All oxime ligand molecules studied for this purpose were optimized in Gaussian09 program using B3LYP function by Density Functional Theory (DFT) and 6-311G(d,p) basic set. HOMO, LUMO and HOMO-LUMO energy gaps of all optimized molecules were calculated. The relationship between quantum chemical parameters and inhibition activities for the ligands studied were also investigated. Binding studies of ligand molecules with molecular docking method by selected proteins were performed using optimized geometries of the ligands. The crystal structures of selected proteins from the Protein Data Bank were provided in *.pdb format and their interaction with optimized ligands was investigated using the SwissDock web server. As a result of the molecular docking studies, ligand-protein binding energies were determined by determining the number of hydrogen bond regions that could occur between the ligand-protein.
\end{abstract}

\section{Giriş}

Yeni ilaçların keşfi, sağlık problemleri ile mücadelede ve insan yaşamının kalitesini artırmak için büyük önem taşımaktadır. Klasik ilaç etken madde sentezi ve ilaç üretimi oldukça maliyetli ve uzun laboratuvar çalışmaları gerektiren bir süreçtir [1, 2]. Teknoloji ile bileşiklerin 3D yapılarının elektronik ortama tanıtılması, yarı deneysel parametrelerin elektronik ortamda hesaplanabilmesi, fizikokimyasal parametrelerin belirlenebilmesi, önder bileşiklerin biyolojik aktiviteleri hakkında yorum yapılabilmesini sağlamıştır. Bu teknolojiye farmakoloji, tıp ve kimya gibi alanların yönelimi ile bilgisayar destekli ilaç tasarımı literatürdeki yerini almaya başlamıştır. Bilgisayar destekli ilaç tasarımı, klasik ilaç üretim sürecinin başlangıç aşamasında bulunduğu katkılarla, düşük maliyet ile kısa bir sürede daha kaliteli bir ilaç 
üretim süreci hedeflemektedir [3-5]. İlaç tasarımı konusunda, protein-ligand kenetlenme (Doking) yöntemleri oldukça önemlidir. Moleküler kenetlenme yeni bir konu olmakla beraber bu alanla ilgili çalışmalar oldukça ilgi çekmekte ve giderek artmaktadır [6-8]. Bu çalışmada, yapısında oksim grubu bulunduran farklı ligandların seçilen proteinleri inhibe etme potansiyelleri ilk defa incelenmiştir.

\section{Materyal ve Metot}

Dört farklı oksim bileşiğinin, seçilmiş bazı proteinlerin aktif bölgesine bağlanma özellikleri, moleküler kenetlenme (Doking) yöntemiyle incelenmiştir. Bu amaçla çalışılan L1, L2, L3 ve L4 ligand moleküllerinin optimize geometrileri, Yoğunluk Fonksiyonel Teorisi (DFT) yöntemiyle B3LYP fonksiyoneli ve 6-311G(d,p) temel seti kullanılarak hesaplanmıştır $[9,10]$.

Tüm kuantum kimyasal hesaplamalar Gaussian09 programında yapılmış, optimize yapılar ve moleküler sınır orbitallere ait görüntüler ise GaussView5.0.9 programı kullanılarak alınmıştır [11, 12]. Moleküler kenetlenme çalışmaları EADock DSS algoritması kullanılarak SwissDock web sunucusunda gerçekleştirilmiştir [13].

Vasküler endotelyal büyüme faktörü reseptörü-2 (PDB ID: 2XIR), siklooksijenaz-2 (PDB ID: 1CX2) ve epidermal büyüme faktörü reseptörünün (PDB ID: 1M17) yüksek çözünürlüklü kristal yapısı, protein veri bankasından (https://www.rcsb.org) elde edilmiştir. Moleküler kenetlenme çalışmalarına ait tüm görüntüleme işlemleri ise UCSF Chimera programı kullanılarak gerçekleştirilmiştir [14].

Moleküler kenetlenme çalışmaları sonucu, ligandprotein bağlanma enerjileri, ligand-protein arasında oluşabilecek hidrojen bağ bölgeleri ve sayısı tespit edilerek değerlendirilmiştir.

\section{Bulgular}

DFT/B3LYP/6-311G(d,p) seviyesinde optimize edilmiş oksim grubu içeren ligandların optimize edilmiş geometrik yapıları Şekil 1-4'de gösterilmektedir.

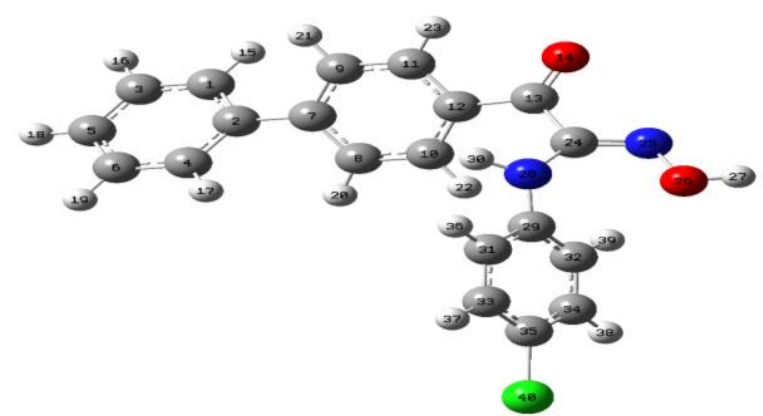

Şekil 1. Ligand L1'in DFT/B3LYP/6-311G(d,p) seviyesinde hesaplanmış optimize yapısı

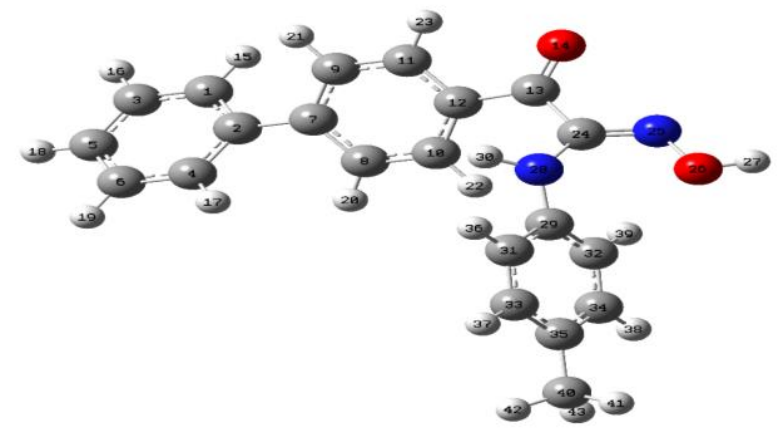

Şekil 2. Ligand L2'in DFT/B3LYP/6-311G(d,p) seviyesinde hesaplanmış optimize yapısı

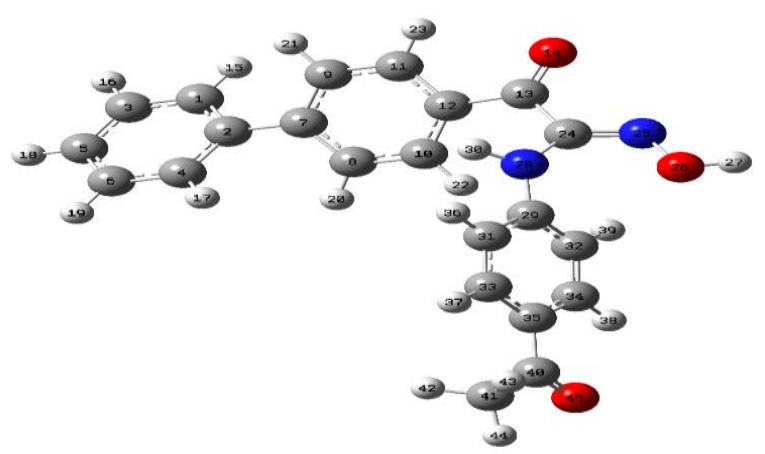

Şekil 3. Ligand L3'ün DFT/B3LYP/6-311G(d,p) seviyesinde hesaplanmış optimize yapısı

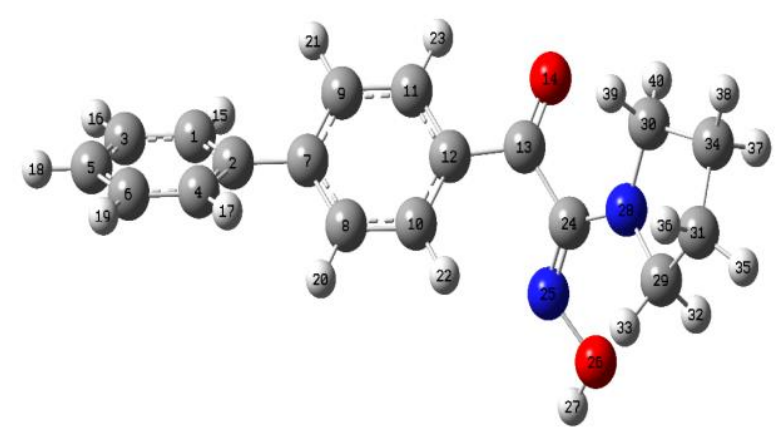

Şekil 4. Ligand L4'ün DFT/B3LYP/6-311G(d,p) seviyesinde hesaplanmış optimize yapısı

Temel olarak, en yüksek dolu moleküler orbital (HOMO) bir molekülün elektron verme kabiliyetini, en düşük boş moleküler orbital (LUMO) ise bir molekülün elektron alma kabiliyetini açıklamakta kullanılır. HOMO ve LUMO arasındaki enerji boşluğu ise, bir molekülün kimyasal kararlılık, elektronik vb. özelliklerinin açıklanmasında oldukça yararlıdır [15]. Herhangi bir molekülün HOMO-LUMO enerji farkının büyük olması durumunda elektron dağılımı daha az değişir, kutuplanma düşük olur ve bu moleküllere sert moleküller denir. HOMO-LUMO enerji farkının küçük olması durumunda ise elektron dağılımı kolayca yönlendirilebilir, kutuplanma büyük olur ve bu moleküllere yumuşak moleküller denir [16]. L1, L2, L3 ve L4 moleküllerinin HOMO ve LUMO orbitalleri TD-DFT/B3LYP/6-311G(d,p) seviyesinde hesaplanmış ve elde edilen üç boyutlu HOMO-LUMO orbitalleri, eV biriminden enerji değerleriyle beraber sırasıyla Şekil 5-8'de verilmiştir. 


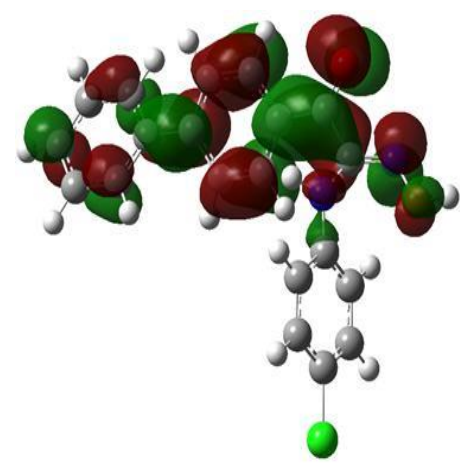

$E($ LUMO $)=-2,124 \mathrm{eV}$

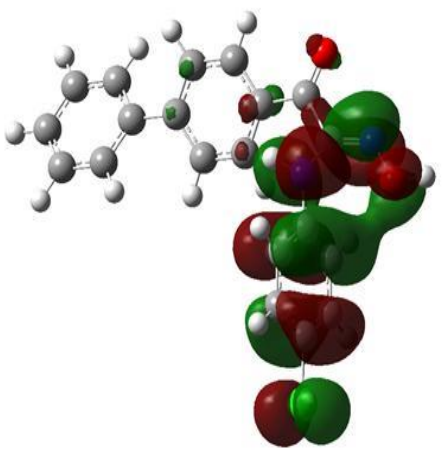

$E(H O M O)=-5,804 \mathrm{eV}$

Şekil 5. Ligand L1'in TD-DFT/B3LYP/6-311G(d,p) seviyesinde hesaplanmış HOMO-LUMO orbitalleri ve enerji değerleri

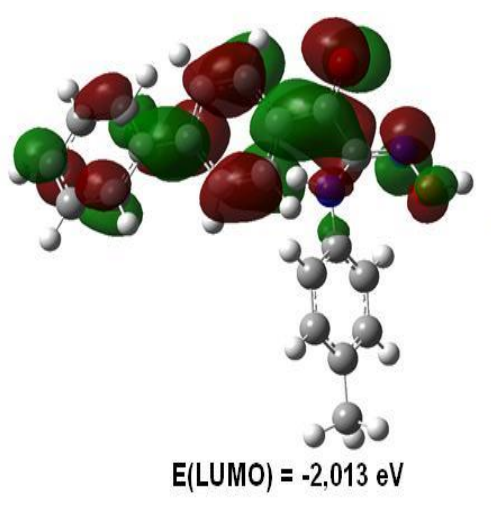

$\Delta \mathbf{E}=3,629 \mathrm{eV}$

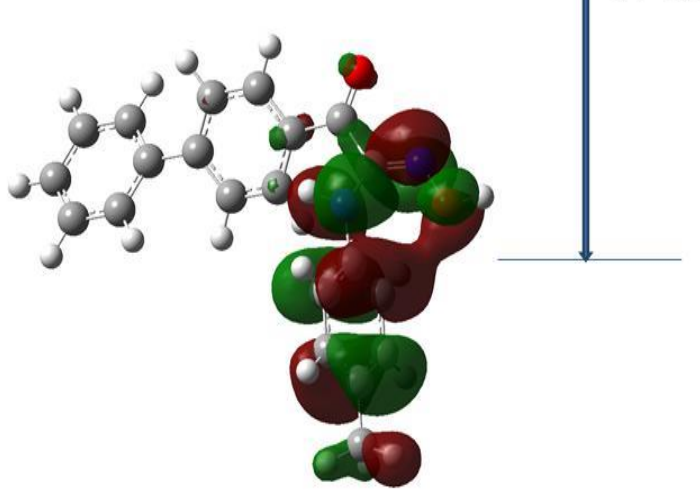

$E(H O M O)=-5,642 \mathrm{eV}$

Şekil 6. Ligand L2'nin TD-DFT/B3LYP/6-311G(d,p) seviyesinde hesaplanmış HOMO-LUMO orbitalleri ve enerji değerleri

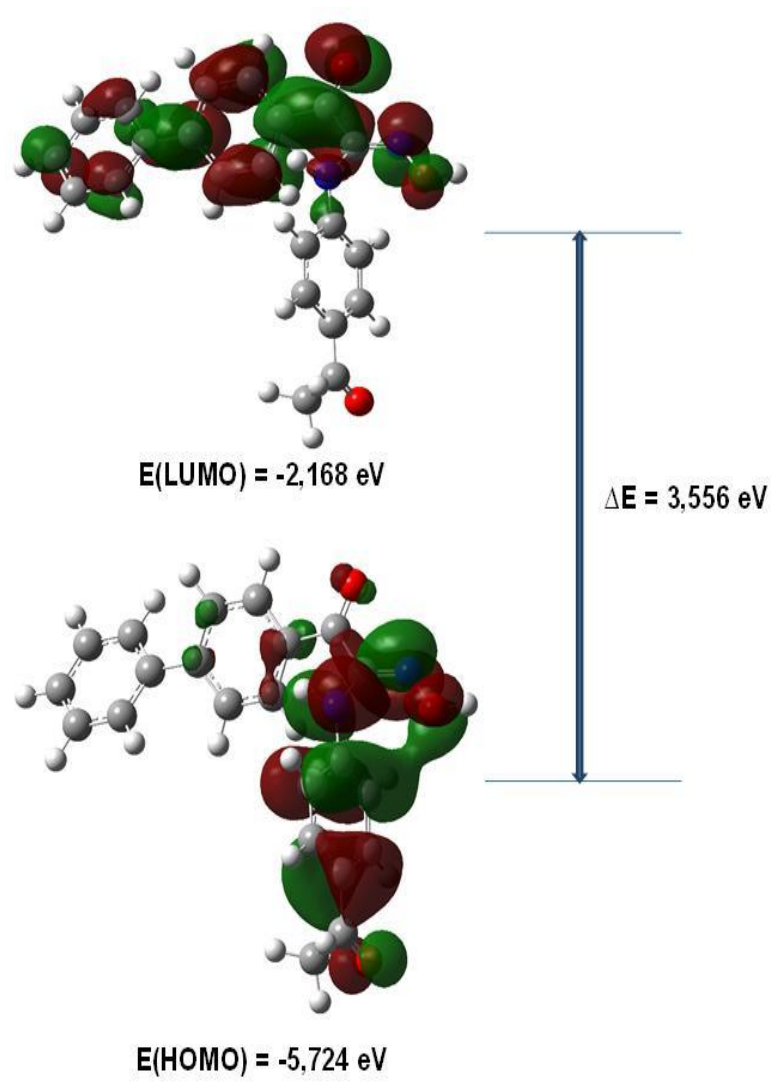

Şekil 7. Ligand L3'ün TD-DFT/B3LYP/6-311G(d,p) seviyesinde hesaplanmış HOMO-LUMO orbitalleri ve enerji değerleri

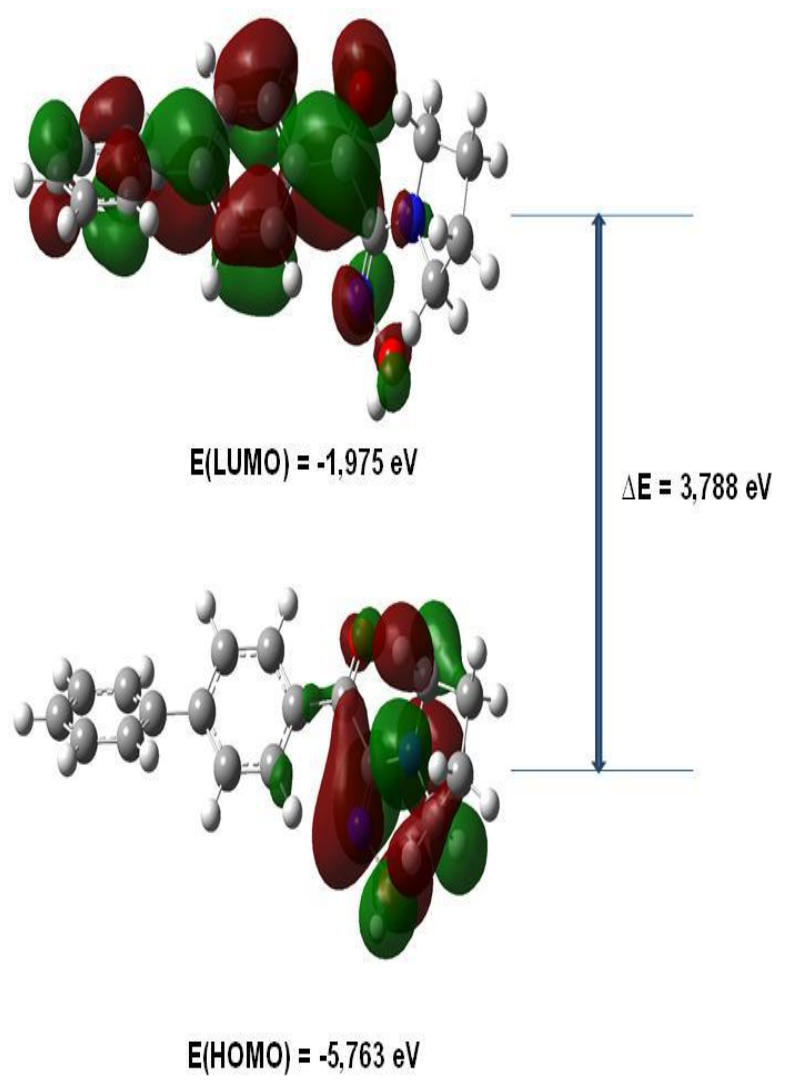

Şekil 8. Ligand L4'ün TD-DFT/B3LYP/6-311G(d,p) seviyesinde hesaplanmış HOMO-LUMO orbitalleri ve enerji değerleri 
Çalışlan moleküllerin HOMO ve LUMO orbitallerinin yapılara olan dağılımı incelendiğinde ortak bir nokta göze çarpmaktadır. Moleküllerin HOMO orbitalleri genellikle amin grubu üzerinde yoğunlaşmışken, LUMO orbitallerinin genellikle bifenil grubu üzerinde kümelendiği belirlenmiştir. Moleküller uyarıldığında elektron geçişinin amin grubunun olduğu bölgeden bifenil grubunun olduğu bölgeye doğru olacağı düşünülmektedir.

Diğer taraftan L1, L2, L3 ve L4 moleküllerinin HOMOLUMO enerji farkı sırasıyla 3.680, 3.629, 3,556 ve 3,788 eV olarak hesaplanmıştır. Bileşikler HOMOLUMO enerji boşluğu açısından değerlendirildiğinde L4>L1>L2>L3 şeklinde bir sıralama elde edilmiştir.
Buna göre en sert ve kararlı molekülün L4 olduğu belirlenmiştir. Yapılan hesaplamalar en yumuşak ve reaktif molekülün ise L3 olduğunu göstermiştir.

L1, L2, L3 ve L4 ligandlarının in silico antitümör aktivitelerini inceleyebilmek amacıyla her bir ligandın moleküler kenetlenme çalışmaları üç farklı protein kullanılarak gerçekleştirilmiştir. Kullanılan proteinler vasküler endotelyal büyüme faktörü reseptörü-2 (VEGFR-2) (PDB ID: 2XIR), siklooksijenaz-2 (COX-2) (PDB ID: 1CX2) ve epidermal büyüme faktörü reseptörüdür (EGFR) (PDB ID: 1M17). Çalıșılan dört ligandın, proteinlerin aktif bölgelerine bağlanmalarından elde edilen parametreler Tablo 1-3'de verilmiştir.

Tablo 1. Ligand-2XIR komplekslerine ait elde edilen parametreler

\begin{tabular}{|c|c|c|c|c|}
\hline $\begin{array}{l}\text { Ligand- } \\
\text { Protein }\end{array}$ & $\begin{array}{c}\Delta G \\
\text { (kkal/mol) }\end{array}$ & $\begin{array}{c}\text { Tam Uyumluluk Skoru } \\
\text { (kkal/mol) }\end{array}$ & $\begin{array}{c}\text { Enerji } \\
\text { (kkal/mol) }\end{array}$ & Hidrojen Bağının Konumu ve Uzunluğu \\
\hline L1-2XIR & -8.17 & -1545.78 & 42.83 & $\begin{array}{c}\text { L1 oksim H \& GLU } 1020 \\
(1.837 \AA) \\
\text { L1 oksim O \& CYS } 104 \mathrm{NH} \\
(2.576 \AA) \\
\text { L1 karbonil O \& CYS } 104 \mathrm{NH} \\
(2.577 \AA) \\
\end{array}$ \\
\hline L2-2XIR & -7.64 & -1543.15 & 47.76 & $\begin{array}{c}\text { L2 oksim O \& İLE } 153 \mathrm{NH} \\
(2.481 \AA \AA) \\
\text { L2 oksim H \& ILE } 1530 \\
(2.377 \AA) \\
\end{array}$ \\
\hline L3-2XIR & -8.55 & -1558.79 & 27.77 & $\begin{array}{c}\text { L3 oksim H \& GLU } 1020 \\
(1.957 \AA) \\
\text { L3 karbonil O \& CYS } 104 \mathrm{NH} \\
(2.384 \AA) \\
\text { L3 asetil O \& ASP } 174 \mathrm{NH} \\
(2.381 \AA)\end{array}$ \\
\hline L4-2XIR & -6.82 & -1540.70 & 50.54 & $\begin{array}{c}\text { L4 oksim H \& SER } 690 \\
(2.665 \AA) \\
\text { L4 oksim O \& CYS } 2 \text { HG1 } \\
(2.219 \AA)\end{array}$ \\
\hline
\end{tabular}

Tablo 2. Ligand-1CX2 komplekslerine ait elde edilen parametreler

\begin{tabular}{|c|c|c|c|c|}
\hline $\begin{array}{c}\text { Ligand- } \\
\text { Protein }\end{array}$ & $\begin{array}{c}\Delta \mathbf{G} \\
\text { (kkal/mol) }\end{array}$ & $\begin{array}{c}\text { Tam Uyumluluk Skoru } \\
\text { (kkal/mol) }\end{array}$ & $\begin{array}{c}\text { Enerji } \\
\text { (kkal/mol) }\end{array}$ & Hidrojen Bağının Konumu ve Uzunluğu \\
\hline L1-1CX2 & -8.10 & -2362.01 & 39.76 & $\begin{array}{c}\text { L1 oksim H \& ASN 34 OD1 } \\
(2.415 \AA)\end{array}$ \\
\hline L2-1CX2 & -9.30 & -2383.63 & 18.05 & $\begin{array}{c}\text { L1 oksim O \& ASN 34 HD22 } \\
(2.382 \AA) \\
\text { L1 amin H \& GLY 135 0 } \\
(2.547 \AA)\end{array}$ \\
\hline L3-1CX2 & -9.22 & -2370.22 & 29.92 & $\begin{array}{c}\text { L2 karbonil O \& ARG 44 NH } \\
(2.145 \AA)\end{array}$ \\
\hline L4-1CX2 & -8.31 & -2367.68 & 32.69 & $\begin{array}{c}\text { L3 asetil O \& CYS 47 NH } \\
(2.061 \AA)\end{array}$ \\
\hline
\end{tabular}


Tablo 3. Ligand-1M17 komplekslerine ait elde edilen parametreler

\begin{tabular}{|c|c|c|c|c|}
\hline $\begin{array}{l}\text { Ligand- } \\
\text { Protein }\end{array}$ & $\begin{array}{c}\Delta G \\
\text { (kkal/mol) }\end{array}$ & $\begin{array}{c}\text { Tam Uyumluluk Skoru } \\
\text { (kkal/mol) }\end{array}$ & $\begin{array}{c}\text { Enerji } \\
\text { (kkal/mol) }\end{array}$ & Hidrojen Bağının Konumu ve Uzunluğu \\
\hline L1-1M17 & -8.11 & -2135.71 & 46.05 & $\begin{array}{c}\text { L1 karbonil O \& MET } 769 \mathrm{NH} \\
(2.293 \AA) \\
\text { L1 amin H \& GLU } 57 \text { N1 } \\
(1.409 \AA)\end{array}$ \\
\hline L2-1M17 & -7.40 & -2133.07 & 47.18 & $\begin{array}{c}\text { L2 oksim O \& MET } 769 \mathrm{NH} \\
(2.345 \AA) \\
\text { L2 oksim H \& GLN } 7670 \\
(2.199 \AA)\end{array}$ \\
\hline L3-1M17 & -8.32 & -2143.92 & 32.27 & $\begin{array}{c}\text { L3 oksim O \& MET } 769 \mathrm{NH} \\
(2.210 \AA)\end{array}$ \\
\hline L4-1M17 & -6.82 & -2127.79 & 53.14 & $\begin{array}{c}\text { L4 oksim H \& LEU } 6940 \\
(1.941 \AA \AA) \\
\text { L4 karbonil O \& CYS } 773 \mathrm{NH} \\
(2.233 \AA \AA)\end{array}$ \\
\hline
\end{tabular}

\section{Tartıșma ve Sonuç}

Ligandların proteinlerle etkileşime girmesi sonucunda elde edilen bağlanma enerjilerine (Gibbs serbest enerjisi, $\Delta \mathrm{G}$ ) bakıldığında her bir etkileşimin ekzotermik olduğu ve istemli bir şekilde gerçekleştiği görülmüştür. Ligand-protein etkileşim düzeyini belirlemede tam uyumluluk skoru (full fitness score) da önemli bir yer tutmaktadır. Ligandların üç farklı proteinle gerçekleştirdiği etkileşimlerin tam uyumluluk skorları incelendiğinde en düşük değerlere ligand-1CX2 komplekslerinde ulaşılmıştır. $\mathrm{Bu}$ sonuç ligandların, 1CX2 kodlu proteinin aktif bölgesine daha iyi yerleştiği anlamına gelmektedir.

Ligandların 2XIR ile etkileşimleri incelendiğinde, bağlanma enerjilerinin $(-8,55)-(-6,82) \quad \mathrm{kkal} / \mathrm{mol}$ arasında, tam uyumluluk skorlarının ise $(-1558,79)-(-$ $1540,70) \mathrm{kkal} / \mathrm{mol}$ arasında olduğu hesaplanmıştır. Ligand-2XIR arasındaki etkileşimlerden en güçlü

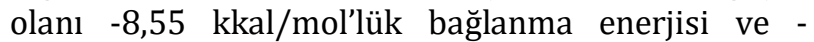
$1558,79 \mathrm{kkal} / \mathrm{mol}$ tam uyumluluk skoru ile L3-2XIR arasında gerçekleşmiştir. L3 ile 2XIR arasında üç hidrojen bağı meydana gelmiştir. Bunlardan ilki L3 ligandının oksim protonu ile GLU 102 oksijen atomu arasında (1,957 ̊̊), ikincisi L3 ligandının karbonil oksijeni ile CYS $104 \mathrm{NH}$ protonu arasında $(2,384 \AA)$, üçüncüsü ise L3 ligandının asetil oksijeni ile ASP 174 NH protonu arasında $(2,381 \AA$ ) gerçekleşmiştir.

L1, L2, L3 ve L4 ligandları en iyi etkileşimi 1CX2 proteini ile meydana gelmiştir. Ligand-1CX2 çiftlerinin bağlanma enerjileri $(-9,30)-(-8,10)$ $\mathrm{kkal} / \mathrm{mol}$ arasında iken tam uyumluluk skorları (2383,63)-(-2362,01) $\mathrm{kkal} / \mathrm{mol}$ arasında bulunmuştur. 1CX2 ile en kuvvetli bir şekilde bağlanan ve en düşük kompleks enerjisine sahip olan ligand L2'dir. L2 ligandının karbonil oksijeni ile 1CX2 proteininin ARG $44 \mathrm{NH}$ protonu arasında 2,145 $\AA$ uzunluğunda bir hidrojen bağı oluşmuş olup bu etkileşime ait bağlanma enerjisi $-9,30 \mathrm{kkal} / \mathrm{mol}$, tam uyumluluk skoru ise $-2383,63 \mathrm{kkal} / \mathrm{mol}$ olarak hesaplanmıştır (Şekil 9).

Ligandların son moleküler kenetlenme çalışması ise $1 \mathrm{M} 17$ kodlu protein kullanılarak gerçekleştirilmiştir. Elde edilen en iyi bağlanma pozlarından hareketle ligand-1M17 komplekslerinin bağlanma enerjileri (8,32)-(-6,82) kkal/mol arasında, bu bağlanmalara ait tam uyumluluk skorları ise $(-2143,92)-(-2127,79)$ $\mathrm{kkal} / \mathrm{mol}$ arasında hesaplanmıștır. Bu sonuçlara göre $1 \mathrm{M} 17$ ile en iyi etkileșime giren ligand 2XIR proteininde olduğu gibi L3'dür. L3 proteinin 1M17 proteinine en iyi bağlanma pozuna ait bağlanma enerjisi $-8,32 \mathrm{kkal} / \mathrm{mol}$, tam uyumluluk skoru ise $2143,92 \mathrm{kkal} / \mathrm{mol}$ olarak bulunmuştur ve L3 ligandının oksim oksijeni ile MET $769 \mathrm{NH}$ protonu arasında $2,210 \AA$ uzunluğunda hidrojen bağ meydana gelmiştir.
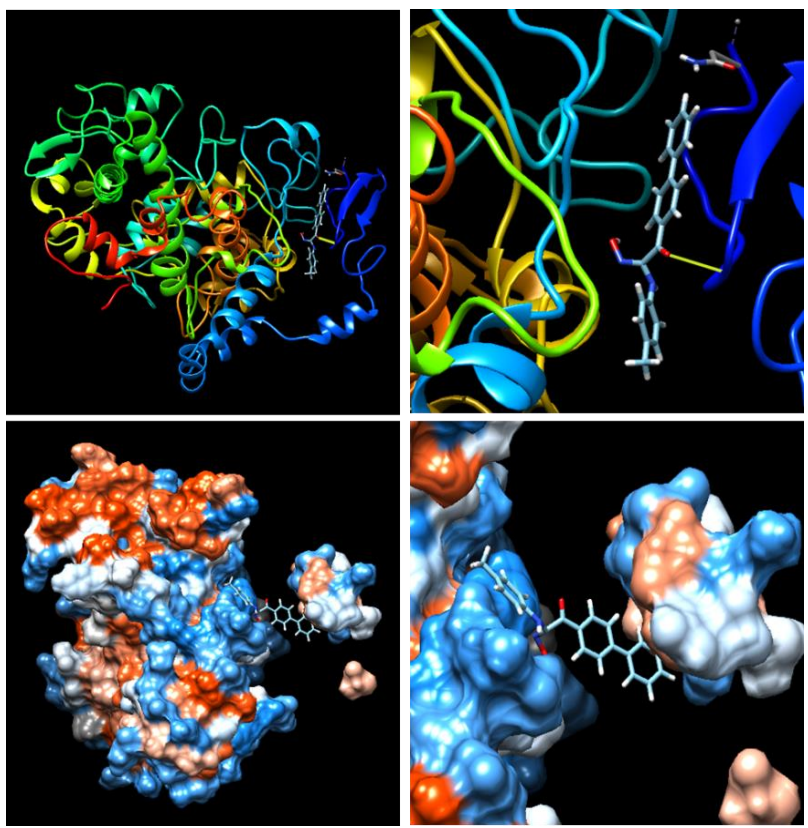

Şekil 9. L2 ligandının 1CX2 kodlu proteine bağlanma (yukarıda) ve aktif alanına yerleșme (aşağıda) pozu 
Sonuç olarak, bu çalışmada kimya ve farmakolojide önemli gruplardan bir tanesi olan oksim grubu içeren dört ligand seçilmiş ve bu moleküllerin geometrik yapılarının optimizasyonları DFT/B3LYP/6311G(d,p) seviyesinde gerçekleştirilmiştir. Ligandların proteinlerle etkileşimlerine katkı sağlayabilmesi amacıyla her bir ligandın HOMOLUMO'ları da hesaplanmıștır.

Hesaplanan HOMO-LUMO enerji farklarından en yumuşak ve reaktif ligandın 3,556 eV ile L3 olduğu, ikinci sırada ise 3.629 eV ile L2 ligandının yer aldığı belirlenmiştir. $\mathrm{Bu}$ sonuç, moleküler kenetlenme çalışmalarından elde edilen sonuçların değerlendirilmesinde oldukça yarar sağlamıştır. Moleküler kenetlenme sonuçları incelendiğinde 2XIR ve 1M17 kodlu proteinlerle en iyi L3 ligandının, 1CX2 kodlu protein ile en iyi L2 ligandının etkileşime girdiği tespit edilmiştir. Buradan hareketle HOMOLUMO enerji boşluğu küçük olup yumuşak olarak nitelendirilen L3 ve L2 ligandlarının bu özelliklerinden dolayı proteinlerle daha iyi etkileşime girdiği söylenebilir.

$\mathrm{Bu}$ çalışmada moleküler kenetlenme özellikleri incelenen tüm ligandlar, seçilen proteinlerin reseptörlerine bağlanmasına rağmen L3 ve L2 ligandları VEGFR-2, COX-2 ve EGFR'yi daha iyi inhibe etmiştir. $\mathrm{Bu}$ sonuçların potansiyel antikanser ilaç geliştirme çalışmalarına katkı sağlayacağı düşünülmektedir.

\section{Teşekkür}

Çalışmayı FYL-2018-6914 No`lu proje ile maddi olarak destekleyen Süleyman Demirel Üniversitesi Bilimsel Araştırma Projeleri Koordinasyon Birimi'ne teşekkür ederiz.

\section{Kaynakça}

[1] Snodin, D. J. 2002. An EU perspective on the use of in vitro methods in regulatory pharmaceutical toxicology. Toxicology Letters, 127(1-3), 161168.

[2] Kraljevic, S., Stambrook, P. J., Pavelic, K. 2004. Accelerating drug discovery. EMBO Reports, 5(9), 837-842.

[3] Baig, M. H., Ahmad, K., Roy, S., Ashraf, J. M., Adil, M., Siddiqui, M. H., Khan, S., Kamal, M. A., Provazník, I., Choi, I. 2016. Computer aided drug design: success and limitations. Current Pharmaceutical Design, 22(5), 572-581.

[4] Baig, M. H., Ahmad, K., Rabbani, G., Danishuddin, M., Choi, I. 2018. Computer aided drug design and its application to the development of potential drugs for neurodegenerative disorders. Current Neuropharmacology, 16(6), 740-748.
[5] Scotti, L., Tullius Scotti, M. 2015. Computer aided drug design studies in the discovery of secondary metabolites targeted against agerelated neurodegenerative diseases. Current Topics in Medicinal Chemistry, 15(21), 22392252.

[6] Rohs, R., Bloch, I., Sklenar, H., Shakked, Z. 2005. Molecular flexibility in ab initio drug docking to DNA: binding-site and binding-mode transitions in all-atom Monte Carlo simulations. Nucleic Acids Research, 33(22), 7048-7057.

[7] Guedes, I. A., de Magalhães, C. S., Dardenne, L. E. 2014. Receptor-ligand molecular docking. Biophysical Reviews, 6(1), 75-87.

[8] Agarwal, S., Chadha, D., Mehrotra, R. 2015. Molecular modeling and spectroscopic studies of semustine binding with DNA and its comparison with lomustine-DNA adduct formation. Journal of Biomolecular Structure and Dynamics, 33(8), 1653-1668.

[9] Becke, A. D. 1988. Density-functional exchangeenergy approximation with correct asymptotic behavior. Physical Review A, 38(6), 3098-3100.

[10] Lee, C., Yang, W., Parr, R. G. 1988. Development of the Colle-Salvetti correlation-energy formula into a functional of the electron density. Physical Review B, 37(2), 785-789.

[11] Frisch, M. J., Trucks, G. W., Schlegel, H. B., Scuseria, G. E., Robb, M. A., Cheeseman, J. R., Scalmani, G., Barone, V., Petersson, G. A., Nakatsuji, H., Li, X., Caricato, M., Marenich, A., Bloino, J., Janesko, B. G., Gomperts, R., Mennucci, B., Hratchian, H. P., Ortiz, J. V., Izmaylov, A. F., Sonnenberg, J. L., Williams-Young, D., Ding, F., Lipparini, F., Egidi, F., Goings, J., Peng, B., Petrone, A., Henderson, T., Ranasinghe, D., Zakrzewski, V. G., Gao, J., Rega, N., Zheng, G., Liang, W., Hada, M., Ehara, M., Toyota, K., Fukuda, R., Hasegawa, J., Ishida, M., Nakajima, T., Honda, Y., Kitao, O., Nakai, H., Vreven, T., Throssell, K., Montgomery, J. A. Jr., Peralta, J. E., Ogliaro, F., Bearpark, M., Heyd, J. J., Brothers, E., Kudin, K. N., Staroverov, V. N., Keith, T., Kobayashi, R., Normand, J., Raghavachari, K., Rendell, A., Burant, J. C., Iyengar, S. S., Tomasi, J., Cossi, M., Millam, J. M., Klene, M., Adamo, C., Cammi, R., Ochterski, J. W., Martin, R. L., Morokuma, K., Farkas, O., Foresman, J. B., Fox, D. J. 2016. Stratmann: Gaussian 09, Revision E.01, Gaussian Inc., Wallingford CT.

[12] Dennington, R., Keith, T. A., Millam, J. M. 2009. GaussView, Revision 5.0.9, Semichem. Inc., Shawnee Mission, KS.

[13] Grosdidier, A., Zoete, V., Michielin, O. 2011. SwissDock, a protein-small molecule docking web service based on EADock DSS. Nucleic Acids Research, 39(suppl_2), W270-W277. 
[14] Pettersen, E. F., Goddard, T. D., Huang, C. C., Couch, G. S., Greenblatt, D. M., Meng, E. C., Ferrin, T. E. 2004. UCSF Chimera-a visualization system for exploratory research and analysis. Journal of Computational Chemistry, 25(13), 1605-1612.

[15] Fukui, K. 1982. Role of frontier orbitals in chemical reactions. Science, 218(4574), 747754.

[16] Pearson, R. G. 1986. Absolute electronegativity and hardness correlated with molecular orbital theory. Proceedings of the National Academy of Sciences, 83(22), 8440-8441. 